\title{
Analysis of caesarean sections using Robson's classification system in a tertiary care centre in Northern India: an emerging concept to audit the increasing caesarean section rate
}

\author{
Deepika Jamwal*, Pallavi Sharma, Anil Mehta, Jiteshwar Singh Pannu
}

Department of Obstetrics and Gynaecology GMC Kathua, Jammu and Kashmir, India

\author{
Received: 01 May 2021 \\ Revised: 15 May 2021 \\ Accepted: 17 May 2021 \\ *Correspondence: \\ Dr. Deepika Jamwal, \\ E-mail: deepikajamwal215@gmail.com
}

Copyright: $(\subset$ the author(s), publisher and licensee Medip Academy. This is an open-access article distributed under the terms of the Creative Commons Attribution Non-Commercial License, which permits unrestricted non-commercial use, distribution, and reproduction in any medium, provided the original work is properly cited.

\begin{abstract}
Background: There has been an increase in rate of caesarean section over last five decades. This is a matter of international public health concern as it increases the caesarean section related maternal morbidity. The aim of the present study was to evaluate that in a new medical college which clinical situation contributed and led to caesarean deliveries as per Robson's classification system and to audit the increasing rate of caesarean section.

Methods: This study was performed in Government Medical College Kathua in the Union territory of Jammu and Kashmir from November 2020 to April 2021. In the present study, all cases delivered by caesarean section during the period of six months were recorded and classified according to Robson's 10 group classification system.

Results: Out of total 1366 women delivered, 630 underwent CS (46.12\%). It was observed that majority of caesarean sections belonged to group 2 and group 5 of Robson criteria. Group 5 comprised of patients with one or more previous caesarean section with cephalic presentation according to Robson criteria and maximum number of caesarean sections done in the present study belonged to this group that is $40.3 \%$. Group 2 that is nulliparous singleton cephalic $>37$ week induced labour or caesarean section before labour comprised 29.2\%. Breech pregnancies (groups 6 and 7 ) had $>90 \%$ caesarean rates.

Conclusions: Women with a previous caesarean delivery represent an increasing proportion of caesarean deliveries. Use of the Robson criteria allows standardized comparisons of data and identifies clinical scenarios driving changes in caesarean rates. Hospitals and health organizations can use the Robson 10-Group Classification System to evaluate quality and processes associated with caesarean delivery.
\end{abstract}

Keywords: Caesarean section, Robson's classification

\section{INTRODUCTION}

The Caesarean delivery rates have been on the rise in the last few decades throughout the world going up to 50-60\% in many centres.1-4 It has increased from a rate of 5\% in 1940 s and 1950 s to $15 \%$ in 1970 and 1980s. However there has been a dramatic increase in the caesarean section rate globally, even beyond $30 \%$ in some areas. The increasing rate of caesarean section is a matter of international public health concern as it increases maternal morbidity. ${ }^{5-7}$ Hence arose the need of standardization of classification of caesarean section through Robson criteria within the healthcare facilities as proposed by Robson in the year 2001. The 10 group Robson classification of caesarean section has been appreciated by WHO in 2014 and FIGO in $2016 .^{8}$ According to WHO, Robson classification will aid in optimisation of the caesarean section use, assessment of the strategies aimed to decrease the 
caesarean section rate and thus improve the clinical practises and quality of care in various health care facilities.

\section{Aim of the study}

The present study was done to analyse caesarean sections using Robson's Ten Group Classification system (TGCS) and determine the groups of patients which contribute the most to caesarean sections in the study group over a period of six months. This will subsequently enable initiation of interventions in the identified groups to reduce the caesarean rates.

\section{Objectives of the study}

To classify the caesarean section according to indications using Robson's TGCS. To identify and audit the rising causes of caesarean section in our scenario.

\section{METHODS}

The present study was carried out retrospectively over a period of six months from November 2020 to April 2021 in the department of Obstetrics and Gynaecology, Government Medical College Kathua, Jammu and Kashmir, India. All data was retrieved and entered in a preformed structured performa.

\section{Inclusion criteria}

Patients delivered by caesarean section during the given period (November 2020- April 2021) were recorded and classified according to Robson's 10 group classification system as given in Table 1.

The parameters considered were according to the classification system: parity (with/ without previous CS), gestational age $(>37 /<36$ weeks), foetal presentation (cephalic/ breech / abnormal lie), number of foetuses (singleton/ multiple), onset of labour (spontaneous/ induced / pre labour CS). (Table 1).

\section{Exclusion criteria}

Term normal or instrumental vaginally delivered patients. Preterm normal or instrumental vaginally delivered patients.

Data collected was analysed using simple statistical measures like percentage and proportion. Descriptive statistical analysis was done. The study was conducted after taking approval from institutional ethical committee.

\section{RESULTS}

From November 2020 to April 2021 there were a total of 1366 deliveries, of which 630 had caesarean section accounting for an overall caesarean delivery rate of $46.12 \%$. When the data was analysed as shown in Table 2 ; the maximum contribution of caesarean was through Robson's group 5 that is multiparous with prior caesarean section, singleton, cephalic, $\geq 37$ weeks $(40.3 \%)$. There were 256 patients in this group with 254 patients who had caesarean section for previous caesarean section (99.2\%). 2 patients with prior caesarean section delivered vaginally.

\section{Table 1: Robson's classification of caesarean section.}

\begin{tabular}{|ll|}
\hline Groups & \multicolumn{1}{c|}{ Clinical Characteristics } \\
\hline $\mathbf{2}$ & Nulliparous, singleton, cephalic, $\geq 37$ weeks, spontaneous labour \\
\hline $\mathbf{3}$ & $\begin{array}{l}\text { Nulliparous, singleton, cephalic, } \geq 37 \text { weeks, induced labour or caesarean section before labour } \\
\text { Multiparous without previous caesarean section, singleton, cephalic, } \geq 37 \text { weeks, spontaneous }\end{array}$ \\
\hline $\mathbf{4}$ & $\begin{array}{l}\text { Multiparous without previous caesarean section, singleton, cephalic, } \geq 37 \text { weeks, induced labour or } \\
\text { caesarean section before labour }\end{array}$ \\
\hline $\mathbf{5}$ & Multiparous with prior caesarean section, singleton, cephalic, $\geq 37$ weeks \\
\hline $\mathbf{6}$ & All nulliparous breeches \\
\hline $\mathbf{8}$ & All multiparous breeches (including previous caesarean section) \\
\hline $\mathbf{9}$ & All multiple pregnancies (including previous caesarean section) \\
\hline $\mathbf{1 0}$ & All pregnancies with transverse or oblique lie (including those previous caesarean section) \\
\hline
\end{tabular}

This was followed by group 2 that is nulliparous, singleton, cephalic, $\geq 37$ weeks, induced labour or caesarean section before labour which contributed $29.2 \%$ to total caesarean section rate. Induction of labour increased the chances of caesarean section in group 2 .

The caesarean section rate in group 1 (nulliparous, singleton, cephalic, $\geq 37$ weeks, spontaneous labour)
(32\%) and 3 (multiparous without previous caesarean section, singleton, cephalic, $\geq 37$ weeks, spontaneous labour) $(3.96 \%)$ was less as they came in spontaneous labour as compared with group 2 ( nulliparous, singleton, cephalic, $\geq 37$ weeks, induced labour or caesarean section before labour) ( $61.7 \%$ ) and group 4 ( multiparous without previous caesarean section, singleton, cephalic, $\geq 37$ weeks, induced labour or caesarean section before labour) 
$(8.49 \%)$ respectively where the labour was induced (Table $2)$. There was $100 \%$ caesarean rate in group 6 with nulliparous breeches whereas 11 out of $12(91.6 \%)$ multiparous breeches had caesarean section in group 7 . One multiparous breech was delivered by full term assisted breech vaginal delivery.

Table 2: Caesarean section rate and contribution made by each group.

\begin{tabular}{|lllll|}
\hline $\begin{array}{l}\text { Robson's } \\
\text { criteria }\end{array}$ & $\begin{array}{l}\text { Total no. of } \\
\text { deliveries in each } \\
\text { group }\end{array}$ & $\begin{array}{l}\text { Total no. of } \\
\text { caesarean section } \\
\text { in each group }\end{array}$ & $\begin{array}{l}\text { Caesarean section } \\
\text { rate }(\%)\end{array}$ & $\begin{array}{l}\text { Contribution made by } \\
\text { each group to total } \\
\text { caesarean section rate }(\%)\end{array}$ \\
\hline $\mathbf{1}$ & 306 & 98 & 32 & 15.5 \\
\hline $\mathbf{2}$ & 298 & 184 & 61.7 & 29.2 \\
\hline $\mathbf{3}$ & 252 & 10 & 3.96 & 1.58 \\
\hline $\mathbf{4}$ & 153 & 13 & 8.49 & 2.06 \\
\hline $\mathbf{5}$ & 256 & 254 & 99.2 & 40.3 \\
\hline $\mathbf{6}$ & 27 & 27 & 100 & 4.28 \\
\hline $\mathbf{7}$ & 12 & 11 & 91.6 & 1.74 \\
\hline $\mathbf{8}$ & 4 & 3 & 75 & 0.47 \\
\hline $\mathbf{9}$ & 4 & 4 & 100 & 0.63 \\
\hline $\mathbf{1 0}$ & 54 & 26 & 48.1 & 4.12 \\
\hline
\end{tabular}

A total 3 out 4 patients with multiple pregnancies in group 8 had caesarean section contributing to $75 \%$. There was $100 \%$ caesarean rate in abnormal lie (group 9). Group 10 contributed $4.12 \%$ to total caesarean section rate.

\section{DISCUSSION}

There is growing international concern about the increased use of caesarean sections (CS), particularly in high-income countries. Caesarean procedures performed in the absence of a clinical justification do not reduce maternal or infant death rates if carried out at a rate higher than 10\%-15\% . ${ }^{9}$ The increasing rate of caesarean section (CS) has been a growing concern in most parts of the world. According to the latest survey 29.7 million $(21.1 \%$, 95\% uncertainty interval 19.9-22.4) births occurred through CS in 2015, which was almost double the number of births by this method in 2000. ${ }^{10}$ WHO has proposed the Robson's ten group classification system (TGCS) as a global standard for assessing, monitoring and comparing CS rates within and between healthcare facilities in 2015 based on two multi country surveys. ${ }^{11-12}$ Several regional and international studies have analyzed the utility of this system to identify factors contributing to increasing CS rates which is a growing global concern. Makhanya et al recommends this system for auditing CS rates within healthcare systems. ${ }^{13}$

In present study, the rate of caesarean section in our hospital $(46.12 \%)$ is quite higher than what has been considered by WHO as $15 \%$ of all deliveries. The caesarean section rate depicted in year 2013-2014 in India was $16.4 \% .{ }^{14}$ This rose to $18 \%$ in $2015-16$ when a health survey was conducted by Nation Family Health Survey. The average caesarean rate in Asian countries (27.3\%) was much lower when compared with USA (31.1\%). ${ }^{15}$
In the present study, the major contribution to overall CS is by group 5 (women with previous CS) followed by group 2. Similar finding has been noted in various Indian and international studies.

Ray et al has shown that women with previous CS contributes maximum to overall CS rates followed by term nulliparous who are induced or underwent CS before labour (group 2 of Robson's classification). ${ }^{16}$ Similar findings were noted by Kazmi et al, Helena et al and Tanaka et al. ${ }^{3,17-18}$ Attempts to reduce repeat CS (by promoting trial of labour after caesarean section) for reducing overall CS rate may be under taken by fullfledged obstetric units with dedicated staff with careful selection of cases.

Labour induction protocols vary worldwide and multiple authors have quoted increasing labour inductions as an upcoming contributor to caesarean deliveries. Study by Ann et al has found induced nulliparous underwent major proportion of primary sections. ${ }^{19}$ In present study also group 2 and 4 had an increased caesarean section rate when compared with 1 and 3 respectively. Hence, the need of the hour is to firstly limit induction of labour. It should be strictly evidence based. Secondly, we should critically evaluate on daily basis the indication of primary caesarean section. This will not only decrease the caesarean section in nulliparous but will also eventually decrease caesarean section in multiparous with previous caesarean section.

Malpresentations, especially breech presentations also contribute significantly to overall as well as primary CS rates in the present study. Sneha et al have noted $100 \%$ CS rate in breech presentations regardless of parity. ${ }^{20}$ Caesareans done for breech presentation can be reduced by training residents in the art of breech delivery. 
Classification under the Robson's classification is the first step on the path to reduce caesarean rates. It is only through periodic analysis using the classification that relevant group specific measures can be introduced. Standardization of indication of caesarean deliveries, regular audits and definite protocols in hospital will aid in curbing the caesarean section rate.

\section{Limitations of the study}

This classification does not include any information regarding indications for induction or CS. It also does not account for pre-existing medical, surgical or foetal disease and the degree of prematurity; all of which may influence the rate of CS. No information regarding women who have undergone Trial of labour after CS (TOLAC) is obtained.

\section{CONCLUSION}

All deliveries and caesareans should be universally categorized by the Robson's classification system. Groups contributing most to caesareans should be analysed regularly and interventions initiated. Those interventions should be targeted at reducing primary caesareans and convincing patients for trial of labour after caesarean section where possible. Inductions should be done only when necessary. A regular audit should be done in all institutions to rationalize caesarean rates. Impact of interventions to reduce caesarean rates should be studied and documented.

\section{ACKNOWLEDGMENTS}

Authors would like to thank the staff of Department of Obstetrics and Gynaecology, Government medical college Kathua for their support during study.

Funding: No funding sources

Conflict of interest: None declared

Ethical approval: The study was approved by the Institutional Ethics Committee

\section{REFERENCES}

1. Hellerstein S, Feldman S, Duan T. China's 50\% caesarean delivery rate: is it too high? BJOG. 2015;122:160-64.

2. Mazzoni A, Althabe F, Liu NH, Bonotti AM, Gibbons L, et al. Women's preference for caesarean section: a systematic review and meta-analysis of observational studies. BJOG. 2011;118:391-99.

3. Tanaka K, Mahomed K. The Ten-Group Robson Classification: A Single Centre Approach Identifying Strategies to Optimise Caesarean Section Rates. Obstet Gynecol Int. 2017;64-8.

4. Aminu M, Utz B, Halim A, Broek NVD. Reasons for performing a caesarean section in public hospitals in rural Bangladesh. BMC Pregnancy Childbirth. 2014;14:130-31.
5. Lumbiganon $\mathrm{P}$, Laopaiboon $\mathrm{M}$, Gulmezoglu AM, Souza JP, Taneepanichskul S, Ruyan P, et al. Method of delivery and pregnancy outcomes in Asia: the WHO global survey on maternal and perinatal health 2007-08. Lancet. 2010;375(9713):490-93.

6. Marshall NE, Fu R, Guise JM. Impact of multiple cesarean deliveries on maternal morbidity: a systematic review. Am J Obstet Gynecol. 2011;205(3):262e1-8.

7. Souza JP, Gülmezoglu AM, Lumbiganon P, Laopaiboon M, Carroli G, Fawole B, et al. Caesarean section without medical indications is associated with an increased risk of adverse short-term maternal outcomes: the 2004-2008 WHO Global Survey on Maternal Perinatal Health. BMC Med. 2010;8(1):71.

8. WHO Statement on Cesarean Section Rates; WHO/RHR/15.02. http://www.who.int/reproductive health/publications/maternal_perinatal_heal th/csstatement/en/. Accessed on 12 April 2021.

9. Cagan M, Tanacan A, Hakli AD, Beksac MS. Changing rates of the modes of delivery over the decades (1976, 1986, 1996, 2006, and 2016) based on the Robson-10 group classification system in a single tertiary health care center. J Matern.-Fetal Neonatal Med. 2019;7058:1-8.

10. Ties B, Carine R, Dessalegn MY, Aluisio BJD, Fernando BC, Liang $\mathrm{J}$ et al. Global epidemiology of use of and disparities in caesarean sections. Lancet. 2018;392(10155)1341-8.

11. Robson M, Murphy M, Byrne F. Quality assurance: the 10-group classification system (Robson classification), induction of labour and cesarean delivery. Int J Gynecol Obstet. 2015:S23-7.

12. Betran AP, Vindevoghel N, Souza JP, Gulmezoglu AM, Torloni MR. A systematic review of the Robson classification for caesarean section: what works, doesn't work and how to improve it. PloS One. 2014;9(6):e97.

13. Makhanya V, Goender L, Moodley J. Utility of Robson ten group classification system to determine appropriateness of caesarean sections at a rural region hospital in Kwazulu-Natal, South Africa. South Africa Med J. 2015;105.

14. Uniceforg 1. UNICEF DATA.[Online]. http://data.unicef.org/topic/maternalhealth/deliverycare/. Accessed on 12 April 2021.

15. MacDorman MF, Menacker F, Declercq E. Cesarean birth in the United States: epidemiology, trends, and outcomes. Clin Perinatol. 2008;35(2):293-307.

16. Ray A, Jose S. Analysis of caesarean section according to Robson's ten group classification system and evaluating the indications within the groups. Int $\mathbf{J}$ Reprod Contracept Obstet Gynecol. 2017;6(2):44751.

17. Kazmi T, Saiseema SV, Khan S. Analysis of caesarean section rate according to Robson's 10 group classification, Oman Med J. 2012;27(5):415-7.

18. Litorp H, Kidanto HL, Nystrom L, Darj E, Essen B. Increasing caesarean section rates among low-risk groups: a panel study classifying deliveries according 
to Robson at a university hospital in Tanzania. Bio Med Centre Pregnancy Childbirth. 2013;13-17.

19. Davey MA, King J. Caesarean section following induction of labor in uncomplicated first births a population based cross sectional analysis of 42950 births. Bio Med Central Pregnancy Childbirth. 2016;16:92.

20. Dhodapkar SB, Bhairavi S, Daniel M, Chauhan NS, Chauhan RC. Analysis of caesarean sections according to Robson's ten group classification system at a tertiary care teaching hospital in south India. Int $\mathbf{J}$ Reprod Contracept Obstet Gynecol. 2015;4(3):74549.

Cite this article as: Jamwal D, Sharma P, Mehta A, Pannu JS. Analysis of caesarean sections using Robson's classification system in a tertiary care centre in Northern India: an emerging concept to audit the increasing caesarean section rate. Int $\mathbf{J}$ Reprod Contracept Obstet Gynecol 2021;10:2281-5. 